\title{
Migração, Colonização e Meio Ambiente: 0 Potencial dos Ecossistemas Amazônicos ${ }^{1}$
}

\author{
Migration, Colonization and Environment: The Potential \\ of Amazonian Ecosystems
}

\author{
Philip M. Fearnside ${ }^{2}$
}

FEARNSIDE, P. M. Migration, Colonization and Environment: The Potential of Amazonian Ecosystems. Cad. Saúde Públ., Rio de Janeiro, 9 (4): 448-457, Oct/Dec, 1993.

Amazonian ecosystems have the capacity to support a sparse human population and to supply irreplaceable environmental services. The region's capacity to produce financial returns through sale of commodities is limited. The production systems presently being used to exploit these ecosystems are unsustainable and do not attend to the basic needs of the region's population, in general offering little employment and little financial return that remains in the region.

Fundamental assumptions of the programs for promoting forestry management and other systems are flawed, and basic changes are necessary in order for these systems to produce in a sustainable way on a commercial scale. Amazonia plays a key role in the supply of environmental services, both in Brazil and in the world as a whole. Institutional mechanisms are needed to assess the value of these services and to translate this value into a means of supporting the people who maintain the forest.

Key words: Human Carrying Capacity; Agricultural Colonization; Forest Management; Climatic Change; Amazonia

\section{PRIMEIRAS CONSIDERAÇÕES}

Para se avaliar o potencial dos ecossistemas amazônicos é necessário, antes de mais nada, definir para qual finalidade o ecossistema tem potencial e para quem os frutos deste potencial estão destinados. Os tipos de potencial de interesse para o planejamento de um desenvolvimento sustentado podem ser divididos em três categorias: potencial para sustentar uma população humana, potencial para gerar um retorno financeiro e potencial para suprir serviços ambientais. É importante ressaltar que a sustentação de uma população humana é algo bem distinto da produção de rendimentos monetários, sendo que muitas das formas atuais de

\footnotetext{
${ }^{1}$ Trabalho apresentado na Conferência Internacional sobre Meio Ambiente, Desenvolvimento e Saúde (CIMADES), 20-24/04/92, Fundação Oswaldo Cruz, Rio de Janeiro.

${ }^{2}$ Instituto Nacional de Pesquisas da Amazônia (INPA). Caixa Postal 478. Manaus, AM, 69011-970, Brasil.
}

desenvolvimento geram lucros sem sustentar uma população significativa dentro da região. Das três categorias de potencial, a de retorno financeiro deve ser secundária às outras duas, uma vez que esta é a mais facilmente substituída por outros meios, além de atender menos às necessidades básicas da população da região. Mesmo assim, não há porque os três objetivos não possam ser alcançados de forma adequada, dentro de um planejamento global.

A primeira questão a ser respondida com respeito ao potencial dos ecossistemas é "potencial para quem?" Considera-se que os benefícios deste potencial devem servir aos atuais residentes da Amazônia e seus descendentes (Fearnside, 1989a). O objetivo deve ser o de fornecer um padrão de vida digno a todos os residentes da região, mantendo, ao mesmo tempo, as funções ambientais da floresta. Tais objetivos não podem incluir o pagamento da dívida externa brasileira, a geração de lucros para as empresas que exploram os recursos 
naturais da região ou a resolução dos problemas sociais e econômicos do restante do Brasil. A Amazônia não pode continuar servindo como um grande sumidouro para os excedentes populacionais que são expulsos pela mecanização da agricultura e pela concentração da posse de terra em locais como o Paraná e o Nordeste do Brasil.

\section{USOS DOS ECOSSISTEMAS}

\section{Colonização Agrícola}

\section{Capacidade de Suporte Humano}

A sustentação de uma população humana somente pode ocorrer dentro dos limites da capacidade de suporte humano, ou seja, a densidade populacional que pode ser mantida por um prazo indefinido utilizando-se uma dada tecnologia produtiva e gozando de um determinado nível de consumo. A capacidade de suporte é bastante limitada, sendo ilusório pensar que a região irá sustentar uma população densa na zona rural. Isto fica evidente nos resultados de um estudo sobre a capacidade de suporte realizado numa área de colonização da rodovia Transamazônica - uma estrada construída no período 1970-1973 com o objetivo declarado de absorver excedentes populacionais do Nordeste brasileiro (Figura 1).
A capacidade de suporte humano é o número de pessoas que podem ser sustentadas, por prazo indeterminado, em uma área, dentro de um determinado padrão de vida, sem que ocorra degradação ambiental, dados pressupostos apropriados sobre a tecnologia utilizada e os hábitos de consumo (Fearnside, 1986). A capacidade de suporte pode ser definida operacionalmente em termos de um gradiente de probabilidades de fracasso dos colonos em face do aumento da densidade populacional (Fearnside, 1989b). As probabilidades de fracasso são tomadas como índices sustentáveis de fracasso durante um longo período de anos, ou seja, índices que não estão sujeitos a tendências de mudança ao longo do tempo. Os critérios culturais seriam utilizados para se definir o termo "fracasso" (definido como uma queda abaixo dos níveis mínimos de consumo especificados para calorias, proteínas totais, proteína animal e dinheiro). A capacidade de suporte equivale à densidade populacional na qual este gradiente excede a probabilidade de fracasso máxima aceitável, fracasso este definido culturalmente (Figura 2).

Assentamentos em Rondônia, estabelecidos para absorver fluxos migratórios do Paraná, mostram o potencial cada vez mais restrito para se absorver populações através da colonização agrícola na Amazônia. Os projetos de colonização "antigos" (da década de 70) tinham $42 \%$ dos seus solos classificados pelo mapeamento

FIG URA 1. Amazônia Legal Brasileira

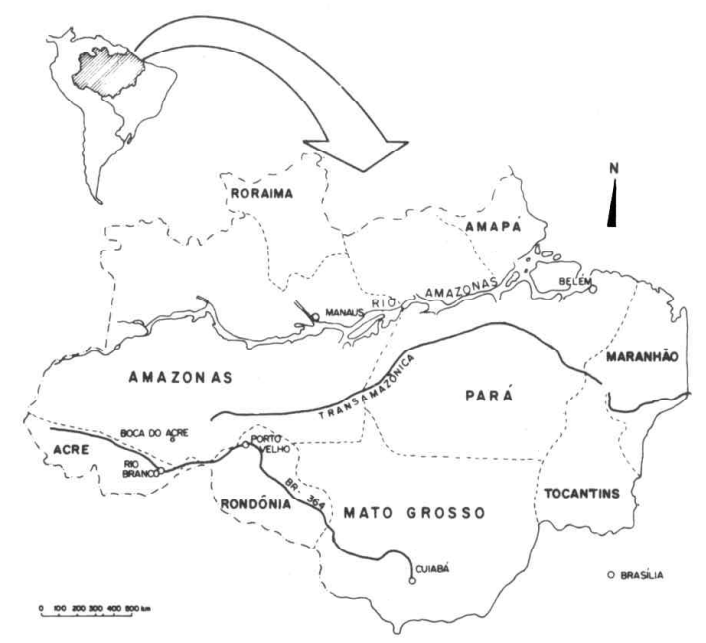


FIG URA 2. A Capacidade de Suporte Humano, Operacionalmente Definida em Termos de um Gradiente de Probabilidades de Fracasso do Colono em Relação à Densidade Populacional

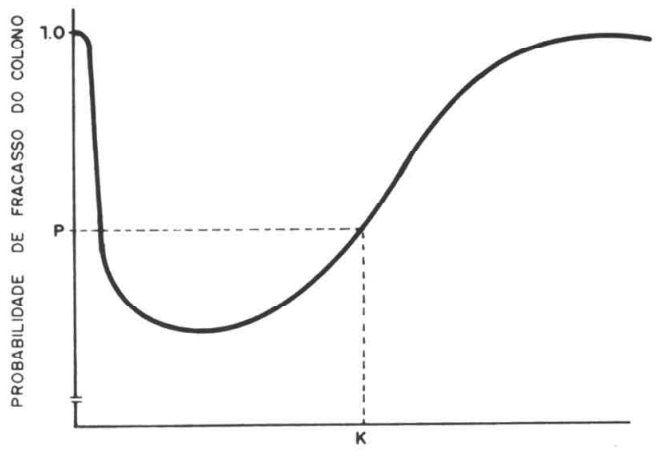

DENSIDADE POPULACIONAL (pessoas $/ \mathrm{km}^{2}$ )

Fonte: Fearnside, 1986.

da Embrapa como sendo "bons para agricultura com insumos baixos ou médios"; nos projetos "novos" (da década de 80), este percentual caiu para 15\%; e nos projetos planejados, não ultrapassa insignificantes $0,13 \%$ (Fearnside, 1987). Isto indica claramente que as áreas com solos melhores têm sido colonizadas primeiro e que as áreas remanescentes terão cada vez menos potencial agrícola. Este padrão, de fato, é uma tendência lógica que vem se repetindo em diversas partes do mundo.

\section{O Estudo da FAO/UNFPA/IIASA}

Um esforço importante para se estimar a capacidade de suporte dos países em desenvolvimento foi levado a cabo em 1982 pela Organização de Alimentação e Agricultura da Organização das Nações Unidas (FAO), em colaboração com o Fundo para Atividades Populacionais da ONU (UNFPA) e com o Instituto Internacional para Análise Aplicada de Sistemas (IIASA) (FAO, 1984; Higgins et al., 1982). Toda a Amazônia brasileira foi mapeada no estudo da FAO/UNFPA/IIASA como sendo capaz de sustentar de 5 a 10 pessoas/ha com insumos altos (adubos, mecanização e uma combinação ótima de culturas de sequeiro). Estes cálculos levaram à conclusão de que o Brasil poderia sustentar o incrível número de
7,1 bilhões de pessoas, se altos níveis de insumo, fossem empregados (Higgins et al., 1982). Qualquer tentativa no sentido de converter a região em uma área de agricultura mecanizada de altos insumos encontraria limitações absolutas de disponibilidade de recursos. A Amazônia virtualmente não tem jazidas de fosfato, como indica o mapa das jazidas de fosfato no Brasil, publicado pelo Departamento Nacional de Produção Mineral (Lima, 1976). O custo de transporte deste adubo seria proibitivo e, quando se considera a vasta extensão da Amazônia, o uso pesado de adubos rapidamente esgotaria os estoques globais de fosfato.

Há uma forte tendência no sentido de ver a Amazônia como uma cornucópia em potencial, capaz de resolver os problemas de população e de distribuição das terras, mas os limites impostos à aplicação do tipo de agricultura intensiva de nutrientes sugerido pela FAO fazem com que este potencial seja uma cruel ilusão. Estes limites são melhor ilustrados pela inviabilidade de se aplicar a tecnologia Yurimaguas a qualquer parte significativa da Amazônia. Este sistema para de cultivo contínuo vem sendo testado desde 1972 na Amazônia peruana (Sánchez et al., 1982), mas as peculiaridades do local e da população de agricultores, os pesados subsídios de insumos e de assistência técnica, além de uma resposta pouco encorajadora por parte dos agricultores locais, mesmo sob circunstâncias atipicamente favoráveis, fazem com que a aplicação em larga escala de técnicas intensivas seja algo improvável na Amazônia (Fearnside, 1990a).

Um fator que leva o estudo da FAO/UNFPA/ IIASA a estimar valores elevados para a capacidade de suporte na Amazônia é o pressuposto de que a qualidade das terras em áreas nãocultivadas é igual àquela em áreas já cultivadas. $\mathrm{O}$ estudo até alega que "existem evidências de que a produtividade das reservas pode ser mais alta, mas, para fins de simplicidade, é presumido que a produtividade em potencial das terras não utilizadas é a mesma que a das terras já sob cultivação" (FAO, 1984). Infelizmente, os autores estão seriamente enganados. Como é o caso na maior parte do planeta, as melhores terras são cultivadas primeiro, sendo que a qualidade vai diminuindo progressivamente em novas áreas de assentamento, até que apenas 
terras bastante marginais permanecem, como no caso do Estado de Rondônia, já mencionado anteriormente (Fearnside, 1987).

\section{Pecuária}

A manutenção da produtividade das pastagens é fundamental, principalmente na Amazônia brasileira, onde quase toda a área desmatada acaba sendo convertida para este uso da terra. As pastagens degradam devido, inclusive, ao esgotamento do fósforo disponível no solo (Fearnside, 1980). A erosão do solo medida em pastagens é mais alta do que aquela medida em florestas - o que implica um desgaste significativo ao longo do tempo, sendo que as pastagens são vistas como um uso da terra a longo prazo (Fearnside, 1989c). Estes resultados, obtidos nas quadras de medição da erosão mantidas em Rondônia (Ouro Preto do Oeste), Amazonas (Distrito Agropecuário da Suframa), Pará (Transamazônica) e Roraima (Apiaú), mostram a invalidade do pressuposto básico da classificação quanto ao potencial agrícola das terras amazônicas feita pelo Projeto RadamBrasil, que serve como base para a maior parte do planejamento na região amazônica. A classificação do RadamBrasil recomenda para pastagens as terras que são por demais acidentadas para o uso de tratores, com base na crença de que o pasto protege o solo contra a erosão: "considera-se que as terras com forte susceptibilidade à erosão e que não tenham condições para o emprego de uma maquinaria agrícola, comum à agricultura do país, seriam próprias para as pastagens" (Ministério das Minas e Energia, 1978).

A produtividade das pastagens declina em decorrência de diferentes fatores, tais como perda de nutrientes, compactação do solo e invasão de ervas daninhas (Fearnside, 1979). Dados obtidos em Rondônia indicam que uma pastagem com 12 anos produz em torno da metade da matéria seca por ano se comparada a uma pastagem com 3 anos (Fearnside, 1989c).

\section{Exploração Madereira}

A exploração madeireira representa um uso das florestas que sempre se apresenta como opção para as vastas áreas que não podem ser aproveitadas para a agropecuária. Embora exista a possibilidade de se suprir colheitas de maneira sustentável através do manejo florestal, barreiras bastante grandes precisam ser superadas para que estes sistemas tornem-se sustentáveis. As práticas atuais levam à destruição das florestas. Isto não se deve tanto a problemas técnicos com os sistemas de manejo, mas a falhas fundamentais na maneira como são tomadas as decisões.

A destruição de recursos potencialmente renováveis, para se aproveitar de um lucro imediato, não é ocasionado pela falta de visão nem pela falta de entendimento técnico sobre a não-sustentabilidade das práticas utilizadas. No caso das empresas e investidores, destruir as florestas é uma decisão financeiramente racional. Uma vez que a taxa de crescimento das árvores, nas florestas, é limitada a um ritmo lento pela biologia das espécies, não se pode concorrer com retornos financeiros em investimentos alternativos, tais como a bolsa de valores ou a especulação imobiliária. Taxas de desconto em torno de 10\% anuais (após correção pela inflação) são geralmente empregadas em cálculos de avaliação de projetos. Isto inviabiliza o manejo florestal sustentado, que seria indicado como racional, se analisado com taxas de desconto em torno de 3\% anuais. Esta falha básica no sistema de avaliação atual é analisada em detalhe, inclusive com exemplos numéricos, por Fearnside (1989d). Fica claro que novas maneiras de se valorizar as florestas e avaliar propostas de desenvolvimento precisam ser formuladas, como também que esta atividade está recebendo um esforço muito aquém do que seria indicado pela importância do problema. Mudanças básicas no sistema são pré-requisitos para o manejo florestal, o que vale dizer que não se deve fomentar a exploração antes de se efetuar mudanças. Não basta lamentar a dificuldade do problema das taxas de desconto e continuar com os negócios, como sempre ocorre.

\section{VALORIZAÇÃO DAS FLORESTAS}

É necessário que as florestas sejam mantidas pelas razões certas. $\mathrm{O}$ fornecimento de mercadorias, tais como madeira, não deve ser a razão 
principal para se manter uma floresta. Grande parte da correria para se aperfeiçoar sistemas de manejo florestal deve-se à preocupação não com o suprimento sustentado de matéria-prima, mas com a manutenção das florestas por outras razões. Isto também se aplica às propostas bastante encorajadoras para a manutenção de áreas de floresta sob uso sustentado em reservas extrativistas, com a exploração de produtos nãomadeireiros (Fearnside, 1992a). O desafio imediato que se impõe é o de avaliar os serviços ambientais e outros serviços das florestas, cobrar valores monetários correspondentes e montar as estruturas institucionais para que este valor seja repassado aos que efetivamente mantêm as florestas em pé. Os valores a serem mantidos incluem a diversidade biológica e cultural das florestas, a manutenção do estoque de opções em potencial para uso (o que é diferente do fluxo de renda oriunda da venda de produtos, tais como material farmacológico e genético) e a manutenção de parâmetros climáticos globais (tais como os teores atmosféricos de gases que provocam o efeito estufa) e regionais (como a evapotranspiração alimentadora do ciclo hidrológico).

\section{Biodiversidade}

A Amazônia detém a maior extensão de floresta tropical remanescente no mundo. Uma vez que um elevado percentual de espécies vivas pertecentes a quase todos os grupos taxonômicos está presente na floresta, a perda da mesma implica a perda de espécies. A perda de espécies aumenta de forma não-linear à medida que o processo de desmatamento aproxima-se dos últimos vestígios de floresta, como já é o caso em locais tais como a América Central, Madagascar e Índia. Infelizmente, dos 114 tipos de vegetação existentes na Amazônia brasileira, 77 (68\%) ainda não têm nenhum exemplar protegido (Fearnside \& Ferraz, s/d).

\section{Efeito Estufa}

O desmatamento na Amazônia brasileira já representa uma contribuição significativa ao efeito estufa. $\mathrm{O}$ efeito estufa é o processo que leva ao aumento da temperatura média global, através do aumento dos gases atmosféricos que impedem a saída do calor para o espaço. Estes gases incluem o dióxido de carbono $\left(\mathrm{CO}_{2}\right)$, o metano $\left(\mathrm{CH}_{4}\right)$, o óxido nitroso $\left(\mathrm{N}_{2} \mathrm{O}\right)$ e o efeito indireto do monóxido de carbono (CO), todos produzidos pelo desmatamento. Cálculos do Painel Intergovernamental de Mudanças Climáticas (IPCC) indicam que, se continuarem as tendências atuais de liberação dos gases, o aumento de temperatura no próximo século será muito superior aos níveis máximos atingidos no último milênio (Houghton et al., 1990, 1992). Entre outros impactos, estas mudanças implicariam a morte de centenas de milhões de pessoas em países asiáticos (Daily \& Ehrlich, 1990).

Um dos índices utilizados para se avaliar o impacto das emissões é o balanço anual de emissões líquidas, o qual expressa os fluxos de gases que ocorrem em um único ano, considerando-se toda a paisagem da região (e não apenas a área desmatada em um determinado ano).

Tanto a queima de biomassa como a decomposição da parte da biomassa desmatada em anos anteriores que não foi combustada na queimada inicial libera gases. $\mathrm{O}$ balanço anual de emissões líquidas é calculado em 296-300 X $10^{6} t$ para o carbono em forma de $\mathrm{CO}_{2}$, ou $312-$ $324 \times 10^{6} t$ para os gases traços, considerando cenários de alto e baixo emissão de gases traços e as equivalências entre gases adotadas em 1992 pelo IPCC para os efeitos diretos ao longo de um horizonte de 100 anos (Fearnside, s/d).

A contribuição do desmatamento na Amazônia brasileira ao balanço anual de gases do efeito estufa representou aproximadamente $4 \%$ do total em 1990, incluindo as fontes de queima de combustíveis fósseis e de desmatamento. Fica claro que apenas cessar ou rreduzir o desmatamento não seria o suficiente para resolver o problema global do efeito estufa: não há como escapar da conclusão de que a queima de combustíveis fósseis pelos países desenvolvidos tem que diminuir drasticamente nos próximos anos. No entanto, a diminuição do desmatamento representa uma das soluções mais baratas para este problema, isto somado a outras razões que indicam a necessidade de se diminuir a perda de florestas. O contraste entre os impactos e os benefícios do desmatamento é enorme: em 1990, o fluxo de gases do desmatamento na Amazônia brasileira tinha aproximadamente seis 
vezes mais impacto sobre o efeito estufa do que a queima de combustíveis fósseis no Brasil, só que os combustíveis fósseis movimentam praticamente todos os transportes e indústrias do País, enquanto o desmatamento apenas deixa vastas áreas de pastagens degradadas. No nível de desmatamento observado em 1990 (13,8 X $10^{3} \mathrm{~km}^{2} / \mathrm{ano}$ ), parar com a derrubada da floresta na Amazônia brasileira contribuiria mais para combater o aquecimento global do que para duplicar a eficiência do uso de combustível em todos os automóveis do mundo (Fearnside, 1992b).

O efeito estufa tem os seus maiores impactos fora do Brasil, sendo que o aumento da temperatura é maior à medida que aproxima-se dos pólos norte e sul. Isto indica que o desmatamento representa uma oportunidade de negociação com os países da zona temperada. Outros impactos climáticos, tais como alterações do ciclo hidrológico, no entanto, incidiram diretamente sobre o Brasil.

\section{Ciclo Hidrológico}

Várias evidências indicam que metade das precipitações na Amazônia é derivada da água que recicla pela floresta através da evapotranspiração, e não do vapor de água de nuvens provenientes do Oceano Atlântico (Salati et al., 1978). Somente quem vê o rio Amazonas durante as enchentes pode avaliar o imenso volume de água envolvido: o volume que se vê no rio é igual àquele que retorna à atmosfera através das folhas da floresta. As folhas da floresta estão constantemente liberando água, e isto pode ser constatado por qualquer pessoa que amarre um saco plástico sobre um grupo de folhas, pois em apenas alguns minutos o saco ficará internamente revestido de gotas de água, condensadas a partir da evapotranspiração. Somando-se as diversas centenas de bilhões de árvores existentes na Amazônia, uma vasta quantidade de água é devolvida à atmosfera. Uma vez que a evapotranspiração é proporcional à área foliar, a quantidade de água reciclada através da floresta é muito maior que aquela reciclada através das pastagens, especialmente na estação seca, quando as pastagens ficam secas, enquanto a floresta permanece sempre verde.
Esta diferença é acentuada pelo escoamento muito maior de água observado nas pastagens. Quadras de $10 \mathrm{~m}^{2}$ para a medição da erosão do solo e do escoamento superficial necessitam de quatro tambores de 200 litros cada para receberem a água quando colocadas em pastagens limpas, enquanto um tambor (e geralmente apenas um balde pequeno) é mais que o suficente para quadras colocadas na floresta. Aumentos do escoamento de água de uma ordem de grandeza foram detectados perto de Manaus (Amazonas), Altamira (Pará) e Ouro Preto do Oeste (Rondônia) (Fearnside, 1989c). O solo sob as pastagens torna-se rapidamente muito compactado, inibindo a infiltração das águas pluviais (Dantas, 1979). A chuva que cai sobre os solos compactados escoa rapidamente, não ficando, assim, disponível para ser posteriormente liberada para a atmosfera através da transpiração.

A conversão da floresta em pastagens pode tornar a época seca mais longa e severa, uma mudança que pode acabar com a floresta, mesmo se a precipitação atmosférica anual total permanecer a mesma. Muitas árvores da floresta já estão no limite de sua tolerância ao stresse hídrico (Nepstad et al., 1990). Em trechos da floresta isolados por pastagens, perto de Manaus, as árvores que ficam nas bordas da floresta morrem a uma taxa bem maior que aquelas situadas na floresta contínua (Lovejoy et al., 1984). Já que muitas dessas árvores limítrofes morrem "de pé", ao invés de serem derrubadas pelo vento, as condições secas do ar ou de solo perto dos limites da reserva florestal representam uma explicação plausível para tal mortalidade. A precipitação atmosférica na Amazônia é caracterizada por uma tremenda variabilidade de um ano para o outro, mesmo na ausência de desmatamento intensivo. Se a contribuição para a precipitação atmosférica durante a estação seca diminuir, o resultado provavelmente será uma seca severa a cada 20 a 50 anos, a qual mataria muitas árvores de espécies suscetíveis. Uma vez que as árvores da floresta amazônica vivem mais de 200 anos, é bem maior a probabilidade de que elas fiquem sujeitas a uma seca intolerável em alguma época de suas vidas. $\mathrm{O}$ resultado disso seria a substituição da floresta tropical por formas de vegetação arbustiva mais tolerantes à seca, semelhantes ao cerrado do 
Brasil Central. Tal mudança ativaria um processo de realimentação positiva, o qual resultaria em florestas menos densas, que transpiram menos, aumentando a severidade das secas e ocasionando, assim, uma mortalidade de árvores ainda maior e o rareamento das florestas (Fearnside, 1985; Shukla et al., 1990). Isto também aumentaria o risco de incêndios em florestas ainda de pé, a partir de queimadas em pastagens vizinhas (Uhl \& Buschbacher, 1985).

A água proveniente da evapotranspiração na Amazônia também contribui para a ocorrência de chuvas no Centro-Sul do Brasil, onde está localizada a maior parte da agricultura do País (Salati \& Vose, 1984). O movimento de rotação da terra faz com que os ventos predominantes, ao sul da linha do equador, curvem da direção leste-oeste para o sul. O transporte de nuvens nesta direção fica evidente nas imagens do satélite meteorológico GOES.

\section{AVALIAÇÃO DOS RISCOS DO DESMATAMENTO}

A capacidade dos ecossistemas amazônicos depende da escala em que ocorre a conversão da floresta. Um hectare de pastagem pode ser mantido tanto em termos agronômicos como em termos do seu impacto sobre o clima e outros parâmetros, mas aumentando-se as pastagens em muito, chegar-se-á ao ponto da "última gota d'água", quando nem mais um hectare pode ser tolerado. Embora ninguém saiba responder quantos hectares podem ser transformados em pastagem, por exemplo, sem que seja ultrapassada a capacidade do sistema, numa escala macro, de absorver este efeito, pode-se pelo menos indicar alguns fatores que deveriam ser levados em consideração ao se fazer este tipo de determinação.

$\mathrm{O}$ efeito de se acrescentar mais um hectare de pastagem à área já convertida não é exatamente análogo à "última gota d'água", que produziria um resultado de transbordar ou não transbordar. No caso do desmatamento, cada hectare a mais eleva a probabilidade de que ocorram certos impactos, alguns deles catastróficos. É preciso que haja não só uma avaliação de tal efeito sobre a probabilidade de ocorrência destas conseqüências, mas também uma decisão social sobre o valor a ser atribuído aos diferentes níveis de risco de cada tipo de resultado possível.

Existe uma relação inversa entre a severidade de diferentes impactos e a probabilidade máxima aceitável para a ocorrência destes impactos. Um impacto de pequenas consequiências poderia até ter uma probabilidade de $100 \%$ de acontecer e, ainda asssim, não afetar a decisão da sociedade, enquanto um impacto grande (por exemplo, um acidente numa usina nuclear) requer uma margem de segurança bastante grande para garantir que o mesmo não vai acontecer. Uma vez que alguns dos impactos do desmatamento são realmente catastróficos, tais como alteração do regime pluviométrico, a qual afetaria a flamabilidade da floresta, a probabilidade máxima aceitável da sociedade deveria ser colocada a um nível bem baixo. A sociedade deve ser avessa aos grandes riscos. Uma vez estabelecidas a curva e a gravidade de uma mudança provocada pelo desmatamento excessivo, pode-se determinar o nível de risco aceitável (Figura 3).

FIGURA 3. Nível de Risco Aceitável em Relação à Magnitude do Impacto

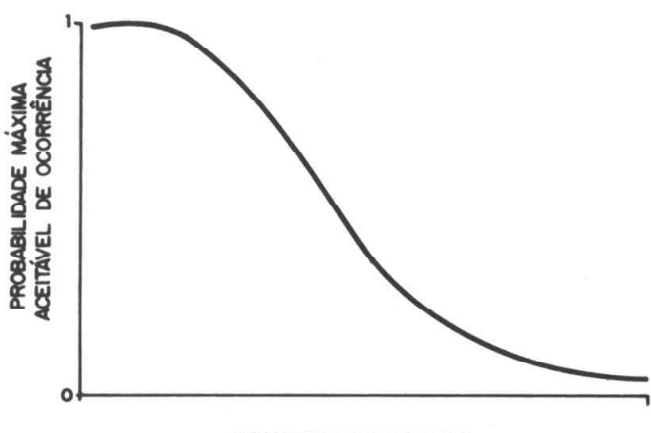

MAGNITUDE DO IMPACTO

Existe também uma relação ainda não muito bem quantificada entre a área desmatada e a probabilidade de ocorrência de mudanças dramáticas. Esta deve ser uma relação positiva, não-linear, onde maiores percentagens da região desmatada correspondam a maiores riscos de impactos catastróficos. Provavelmente, a curva começaria com um aumento pegueno, aumentaria rapidamente em alguma faixa intermediária 
de percentual desmatado e, depois, aproximarse-ia assintoticamente da probabilidade de $100 \%$, em situações de desmatamento muito avançado. Utilizando-se a probabilidade máxima aceitável identificada através da primeira curva (Figura 3), pode-se identificar o percentual a ser considerado como fração de desmatamento máximo aceitável, do ponto de vista deste critério (Figura 4).

FIGURA 4. O Percentual Máximo de Desmatamento Aceitável,

Determinado a partir da Probabilidade Máxima de um Impacto

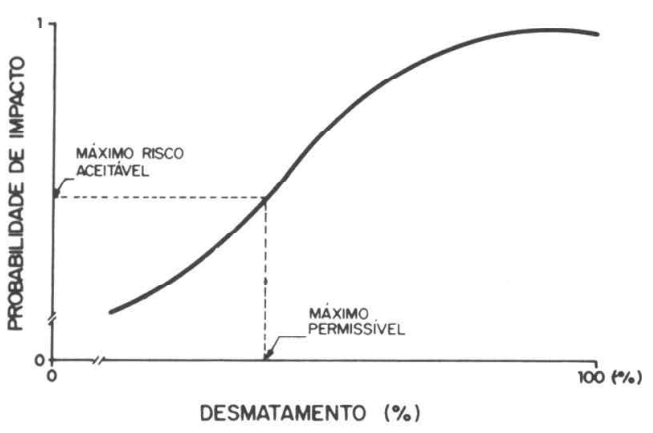

\section{CONCLUSÕES}

A capacidade dos ecossistemas amazônicos de suprir, de forma sustentável, muitos dos produtos que são exigidos da região é limitada. No entanto, desde que sejam respeitados os seus limites, os ecossistemas amazônicos podem sustentar uma população local, mantendo, ao mesmo tempo, os serviços ambientais. É importante que haja uma clara definição acerca de para que e para quem serve a capacidade dos ecossistemas. Esta deve servir ao bem-estar dos residentes da região e seus descendentes. Os objetivos na utilização do potencial destes ecossistemas podem ser divididos em: sustentação de uma população; o suprimento de serviços ambientais; e geração de retornos financeiros. A região pode sustentar uma população esparsa na zona rural, com um nível de vida digno, mas não pode resolver os problemas do restante do País, pagar a dívida externa nacional ou fornecer grandes lucros às empresas que exploram seus recursos. Os atuais sistemas de aproveitamento estão destruindo a floresta, não são sustentáveis e não atendem às necessidades da população da região. Mudanças básicas na maneira de se avaliar as opções de desenvolvimento são pré-requisitos para o estabelecimento de sistemas sustentáveis. Os "produtos" mais valiosos que os ecossistemas amazônicos produzem são os serviços ambientais. É preciso montar, com urgência, mecanismos institucionais para recompensar as populações que mantêm a floresta, com base no valor destes serviços.

\section{AGRADECIMENTOS}

Meus agradecimentos a E. J. G. Ferreira, P. L. M. A. Graça e S. V. Wilson, que fizeram comentários valiosos.

\section{RESUMO}

FEARNSIDE, P. M. Migração. Colonização e Meio Ambiente: O Potencial dos Ecossistemas Amazônicos. Cad. Saúde Públ., Rio de Janeiro, 9 (4): 448-457, out/dez, 1993.

Os ecossistemas amazônicos têm a capacidade de sustentar uma população humana esparsa e suprir serviços ambientais insubstituíveis. Contudo, a sua capacidade de gerar lucros financeiros através da venda de mercadorias é limitada. Os sistemas atualmente utilizados para o aproveitamento dos ecossistemas são insustentáveis e não atendem às necessidades básicas da população da região, geralmente oferecendo poucos empregos e retorno financeiro escasso. Os pressupostos fundamentais dos programas de fomento ao manejo florestal e outros sistemas são falhos, necessitando de mudanças básicas para que possam produzir de forma sustentável em escala comercial. A Amazônia tem um papel chave no suprimento de serviços ambientais, tanto no Brasil como no mundo. São 
necessários mecanismos institucionais para se avaliar estes serviços e traduzir este valor em um meio de sustento para aqueles que mantêm a floresta.

Palavras-Chave: Capacidade de Suporte Humano; Desmatamento; Colonização Agrícola; Manejo Florestal; Mudanças Climáticas; Amazônia

\section{REFERÊNCIAS BIBLIOGRÁFICAS}

DAILY, G. C. \& EHRLICH, P. R., 1990. An exploratory model of the impact of rapid climate change on the world food situation. Proceedings of the Royal Society of London, B 241: 232-244.

DANTAS, M., 1979. Pastagens da Amazônia Central: Ecologia e fauna de solo. Acta A mazonica, 9 (supl.): 1-54.

FAO (Food and Agriculture Organization of the United Nations), 1984. Land, Food and People. Roma: Food and Agriculture Organization of the United Nations. (FAO Economic and Social Development Series, No. 30)

FEARNSIDE, P. M., 1979. Previsão de produção bovina na rodovia Transamazônica do Brasil. Acta A mazonica, 9: 689-700.

, 1980. Os efeitos das pastagens sobre

a fertilidade do solo na Amazônia brasileira: consequiências para a sustentabilidade de produção bovina. Acta A mazonica, 10: 119-132.

1985. Environmental change and deforestation in the Brazilian Amazon. In: Change in the A mazon Basin: M an's Impact on Forests and Rivers (J. Hemming, org.), pp. 70-89, Manchester: Manchester University Press. , 1986. Human Carrying Capacity of the Brazilian Rainforest. New York: Columbia University Press.

1987. Distribuição de solos pobres na colonização de Rondônia. Ciência Hoje, 6: 74-78.

, 1989a. Projetos de colonização na Amazônia brasileira: Objetivos conflitantes e capacidade de suporte humano. Cadernos de Geociências, 2: 7-25.

, 1989b. Um modelo estocástico para a estimativa da capacidade de suporte humano em parte da área de colonização da rodovia Transamazônica. Cadernos de Geociências, 3: 7-36. , 1989c. Ocupação Humana de Rondônia: Impactos, Limites e Planejamento. Brasília: Conselho Nacional de Desenvolvimento Científico e Tecnológico. (CNPq - Relatórios de Pesqui$\mathrm{sa}, \mathrm{n}^{\circ} 5$ )
, 1989d. Manejo florestal na Amazônia: Necessidade de novos critérios na avaliação de opções de desenvolvimento. Pará Desenvolvimento, 25: 49-59.

, 1990a. Reconsideração do cultivo contínuo na Amazônia. Revista Brasileira de Biologia, 50: 833-840.

, 1990b. Human carrying capacity in rainforest areas. Trends in Ecology and Evolution, 5: 192-196.

, 1990c. Predominant land uses in the

Brazilian Amazon. In: Alternatives to Deforestation: Towards Sustainable Use of the Amazon Rain Forest (A. B. Anderson, org.), pp. 235251, New York: Columbia University Press.

, 1992a. Reservas extrativistas: Uma estratégia de uso sustentado. Ciência Hoje, 14: 14-18.

, 1992b. Greenhouse Gas Emissions from Deforestation in the Brazilian Amazon. Carbon Emissions and Sequestration in Forests: Case Studies from Developing Countries. Volume 2. LBL-32758, UC-402, Berkeley: Climate Change Division, Environmental Protection Agency, Washington, DC \& Energy and Environment Division, Lawrence Berkeley Laboratory, University of California. , s/d. Amazonia and global warming: Annual balance of greenhouse gas emissions from land use change in Brazil Amazon region. (em preparação)

FEARNSIDE, P. M. \& FERRAZ, J., s/d. Identifying areas of biological importance in Brazilian Amazonia. In: Priority A reas for Conservation in A mazonian Rainforest (G. T. Prance; T. E. Lovejoy; A. B. Rylands; A. A. dos Santos \& C. Miller, orgs.), Washington, D.C.: Smithsonian Institution Press. (no prelo)

HIGGINS, G. M.; KASSAM, A. H.; NAIKEN, L.; FISCHER, G. \& SHAH, M. M., 1982. Potential Population Supporting Capacities of Lands in the Developing World. Roma: Food and Agriculture Organization of the United Nations.

HOUGHTON, J. T.; CALLANDER, B. A. \& VARNEY, S. K. (orgs.), 1992. Climate Change 1992: The Supplementary Report to the IPCC Scientific Assessment. Cambridge: Cambridge University Press.

HOUGHTON, J. T.; JENKINS, G. J. \& EPHRAUMS, J. J. (orgs.), 1990. Climate Change: The IPCC Scientific Assessment. Cambridge: Cambridge University Press.

LIMA, J. M. G., 1976. Perfil A nalítico dos Fertilizantes Fosfatados. Brasília: Ministério das Minas e Energia, DNPM. (Boletim No 39) 
LOVEJOY, T. E.; RANKIN, J. M.; BIERREGAARD, R. O. Jr.; BROWN, K. S. Jr.; EMMONS, L. H. \& VAN DER VOORT, M. E., 1984. Ecosystem decay of Amazon forest remnants. In: Extinctions (M. H. Nitecki. org.), pp. 295-325, Chicago: University of Chicago Press.

MINISTÉRIO DAS MINAS E ENERGIA, 1978. Projeto RADAMBRASIL, 1973-1982. Levantamento de Recursos Naturais. Vols. 1-23. Rio de Janeiro: Ministério da Minas e Energia, Departamento Nacional de Produção Mineral.

NEPSTAD, D.; UHL, C. \& SERRÃO, E. A., 1990. Surmounting barriers to forest regeneration in abandoned, highly degraded pastures: A case study from Paragominas, Pará, Brazil. In: Alternatives to Deforestation: Towards Sustainable Use of the A mazon Rain Forest (A. B. Anderson, org.), pp. 215-229, New York: Columbia University Press.
SALATI, E. \& VOSE, P. B., 1984. Amazon Basin: A system in equilibrium. Science, 225: 129-138.

SALATI, E.; MARQUES, J. \& MOLION, L. C. B., 1978. Origem e distribuição das chuvas na Amazônia. Interciencia, 3: 200-206.

SÁNCHEZ, P. A.; BANDY, D. E.; VILLACHICA, J. H. \& NICHOLAIDES, J. J. III, 1982. Amazon Basin soils: Management for continuous crop production. Science, 216: 821-827.

SHUKLA, J.; NOBRE, C. \& SELLERS, P., 1990. Amazon deforestation and climate change. Science, 247: 1322-1325.

UHL, C. \& BUSCHBACHER, R., 1985. A disturbing synergism between cattle-ranch burning practices and selective tree harvesting in the eastern Amazon. Biotropica, 17: 265-268. 